This item is the archived peer-reviewed author-version of:

\title{
A graphene/gelatin composite material for the entrapment of hemoglobin for bioelectrochemical sensing applications
}

\section{Reference:}

Thirumalraj alamurugan, Palanisamy Selvakumar, Chen Shen-Ming, De Wael Karolien.- A graphene/gelatin composite material for the entrapment of hemoglobin for bioelectrochemical sensing applications

Journal of the electrochemical society / Electrochemical Society [New York] - ISSN 0013-4651 - 163:7(2016), p. 265-271

Full text (Publishers DOI): http://dx.doi.org/doi:10.1149/2.0341607jes 


\section{A graphene/gelatin composite material for the entrapment of hemoglobin for bioelectrochemical sensing applications}

Balamurugan Thirumalraj $^{\mathrm{a}}$, Selvakumar Palanisamy ${ }^{\mathrm{a}}$, Shen-Ming Chen $^{\mathrm{a}^{*}}$, Karolien De Wael $^{\mathrm{b}}$

${ }^{a}$ Department of Chemical Engineering and Biotechnology, National Taipei University of Technology, Taipei 106, Taiwan (ROC)

${ }^{\mathrm{b}}$ University of Antwerp, Department of Chemistry, Groenenborgerlaan 171, B-2020 Antwerp, Belgium.

Corresponding Author:

*SM. Chen, Fax: +886227025238, Tel: +886227017147, E-mail: $\underline{\text { smchen78@ ms15.hinet.net }}$ 


\begin{abstract}
In the present work, a novel graphene (GN) and gelatin (GTN) composite was prepared and used as an immobilization matrix for hemoglobin ( $\mathrm{Hb}$ ). Compared with $\mathrm{Hb}$ immobilized on a bare, GN or GTN modified glassy carbon electrode (GCE), a stable and pair of well-defined quasi redox couple was observed at an $\mathrm{Hb}$ modified GN/GTN composite GCE at a formal potential of $-0.306 \mathrm{~V}$ versus $\mathrm{Ag} \mid \mathrm{AgCl}$. The direct electrochemical behavior of $\mathrm{Hb}$ was greatly enhanced by the presence of both GTN and GN. A heterogeneous electron transfer rate constant $\left(K_{\mathrm{s}}\right)$ was calculated as $3.82 \mathrm{~s}^{-1}$ for $\mathrm{Hb}$ immobilized at GN/GTN modified GCE, which indicates the fast direct electron transfer of $\mathrm{Hb}$ towards the electrode surface. The biosensor shows a stable and wide linear response for $\mathrm{H}_{2} \mathrm{O}_{2}$ in the linear response range from $0.1 \mu \mathrm{M}$ to $786.6 \mu \mathrm{M}$ with an analytical sensitivity and limit of detection of $0.48 \mu \mathrm{A \mu M}^{-1} \mathrm{~cm}^{-2}$ and $0.04 \mu \mathrm{M}$, respectively. The fabricated biosensor holds its high selectivity in the presence of potentially active interfering species and metal ions. The biosensor shows its satisfactory practical ability in the commercial contact lens solution and human serum samples.
\end{abstract}




\section{Introduction}

Over the past decades, the development of reliable biosensors has received substantial attention in the field of clinical monitoring, food and pharmaceutical research and medical diagnosis [1]. Heme proteins are broadly used in biosensors owing to their high specificity and commercial availability [2]. Compared to unmodified electrodes, the modified electrodes are widely used as an immobilization matrix for heme proteins, since the redox active center of heme protein deeply buried inside the protein matrix [3]. For instance, the metal and metal alloy nanoparticles [4], polymers [5], carbon nanotubes [6] and graphene (GN) [7] have been extensively used as electrical connectors between the electrode surface and the redox centers of heme proteins. In particular, GN is considered as a main building block for all graphite forms and received enormous interest in the materials science and nanotechnology due to the high thermal conductivity, excellent mechanical flexibility and nontoxicity [8-10]. Furthermore, GN has been widely used for different potential applications, such as energy storage, solar cells, data storage, LCD smart windows and OLED displays, solar cells, photocatalysis, electrochemical sensors and biosensors [8,11-15]. However, the direct immobilization of heme proteins on the pristine GN surface is quite difficult due to its hydrophobic nature. In addition, the hydrophobic nature of GN can easily agglomerates to graphite due to the Van der Waals interaction and strong $\pi-\pi$ stacking of individual GN sheets [16]. Therefore, different materials or approaches have been used on the GN surface to prevent the agglomeration of GN sheets and enrich the biocompatibility of the GN [16-18]. Recently, the supramolecular adducts, surfactants and polymers have been widely used for improving the dispersion of GN and prevent the restacking of GN sheets. In addition, the biocompatibility of GN has greatly improved in the presence of surfactants and biopolymers [19-21]. Gelatin (GTN) is a linear polypeptide and denatured product of collagen, which consists of different amounts of 18 amino acids [21]. The triplehelical structure, biodegradability and biocompatibility of GTN have been mainly used for pharmaceutical and medical applications [21]. It has been reported earlier that GTN is a promising dispersing agent and stabilizer for carbon nanotubes (CNT). Besides, the CNT dispersed GTN showed an enhanced biocompatibility than pristine CNT and is often more helpful for immobilization of redox active proteins including heme proteins [22-26]. Due to the aforementioned special properties of GTN, we have successfully used GTN as a dispersing agent for $\mathrm{GN}$ and the resulting composite was used as an immobilization matrix for heme proteins. We have chosen the hemoglobin $(\mathrm{Hb})$ as a model enzyme for our study due to its commercial availability and similar catalytic activity to other heme proteins. To the best of our knowledge, the GN/GTN composite has never been used as an immobilization matrix for any redox active proteins.

Hydrogen peroxide $\left(\mathrm{H}_{2} \mathrm{O}_{2}\right)$ is a small molecule and plays an important role in different fields including textile industry, food analysis, pharmaceutical research, medical diagnostics, environmental and food analysis [27, 28]. It is also widely used in antiseptic and disinfecting agents, cleaning product, propellant in rocket, minerals processes and beverage packages [29, 30]. The most commonly available methods for the detection of $\mathrm{H}_{2} \mathrm{O}_{2}$ are fluorescence, spectrophotometry, chemiluminescence and electrochemical methods [31-35]. Compared with traditional methods, electrochemical methods are widely used for the detection of $\mathrm{H}_{2} \mathrm{O}_{2}$ due to their simplicity, cost effectiveness with high sensitivity [36]. The heme redox active proteins based biosensors have predominantly used for the sensitive and selective detection of $\mathrm{H}_{2} \mathrm{O}_{2}$, owing to the high specificity towards $\mathrm{H}_{2} \mathrm{O}_{2}$ [37]. 
In the present work, a novel hydrogen peroxide biosensor was constructed based on the direct electrochemistry of $\mathrm{Hb}$ immobilized on GN/GTN composite modified glassy carbon electrode (GCE). We did not use any cross-linkers for immobilization of $\mathrm{Hb}$ on GN/GTN composite. The GN/GTN composite was prepared by dispersing the pristine GN in GTN aqueous solution. Compared with $\mathrm{Hb}$ immobilized pristine $\mathrm{GN}$, the $\mathrm{Hb}$ immobilized GN/GTN composite showed a well-defined quasi redox behavior for $\mathrm{Hb}$ showing its applicative potential. The resulting biosensor was further used for the detection of $\mathrm{H}_{2} \mathrm{O}_{2}$ and the practicality of the fabricated biosensor has also been discussed in detail.

\section{Experimental}

Materials and method. - Graphene (GN) nanopowder ( $8 \mathrm{~nm}$ flakes, product number URGNAPHENE) was purchased from UniRegion Bio-Tech, Taiwan. Hydrogen peroxide $\left(\mathrm{H}_{2} \mathrm{O}_{2}\right)$ was obtained from Wako pure chemical industries. Gelatin (GTN) from bovine skin was purchased from Sigma-Aldrich. Human blood serum sample was collected from valley biomedical, Taiwan product \& services, Inc. This study was reviewed and approved by the ethics committee of Chang-Gung memorial hospital through the contract no. IRB101-5042A3. Contact lens (containing 3\% $\mathrm{H}_{2} \mathrm{O}_{2}$ ) solution was purchased from China Chemical and Pharmaceutical, Taipei, Taiwan. The supporting electrolyte was prepared by using $0.05 \mathrm{M} \mathrm{Na} \mathrm{HPO}_{4}$ and $\mathrm{NaH}_{2} \mathrm{PO}_{4}$ solutions in doubly distilled water. All the chemicals used in this work were of analytical grade and all the solutions were prepared using doubly distilled water without any further purification.

A computerized electrochemical workstation CHI1205B was used for cyclic voltammetry (CV) and amperometric i-t measurements. Scanning electron microscopy (SEM) was performed using Hitachi S-3000 H electron microscope. UV-Vis spectroscopy was performed using the JASCO V-770 spectrometer. Raman spectra were recorded using a Raman spectrometer (Dong Woo 500i, Korea) equipped with a charge-coupled detector. X-ray diffraction (XRD) spectroscopy was carried out using XPERT-PRO (PANalytical B.V., The Netherlands) diffractometer $(\mathrm{Cu} \mathrm{K \alpha}$ radiation, $\mathrm{k}=1.54 \AA)$. Amperometric ( $i$ - $t$ curve) measurements were performed using a PRDE-3A (ALS Co., Ltd, Japan, www.bas.co.jp/) rotating ring disc electrode (RDE) apparatus with an electrochemically working surface area (EASA) of $0.038 \mathrm{~cm}^{2}$. The EASA of the modified was calculated from our previously reported method [27]. Conventional three-electrode system was used for the electrochemical experiments, glassy carbon electrode (GCE) was used as a working electrode, a saturated $\mathrm{Ag} / \mathrm{AgCl}$ electrode as a reference electrode and a platinum wire as an auxiliary electrode. All measurements were carried out at room temperature.

The gelatin solution was prepared by dissolving dry gelatin $(1.5 \mathrm{mg} / \mathrm{mL})$ in deionized water under magnetic stirring at $60{ }^{\circ} \mathrm{C}$ for $2 \mathrm{~h}$. The resulting GTN solution was cooled to room temperature and used for further experiments. The GN flakes $(5 \mathrm{mg} / \mathrm{mL})$ were added in $5 \mathrm{~mL}$ of GTN solution and sonicated for $30 \mathrm{~min}$ at room temperature. For fabrication of GN/GTN modified electrode, about $8 \mu \mathrm{L}$ of as prepared GN/GTN solution was drop coated on the precleaned GCE and dried in an air oven. For control electrodes, the GN solution was prepared by dispersing of GN flakes in DMF solution. The GN and GTN modified electrodes were fabricated by drop coating of $4 \mu \mathrm{L}$ of GN and GTN solution on the GCE surface and dried in air oven at $25^{\circ}$

$\mathrm{C}$. The $\mathrm{Hb}$ stock solution was prepared by dissolving of $\mathrm{Hb}\left(5 \mathrm{mg} \mathrm{mL}^{-1}\right)$ in PBS and stored at 4 ${ }^{\circ} \mathrm{C}$ when not in use. About $8 \mu \mathrm{L}$ of $\mathrm{Hb}$ solution was drop coated on as-prepared GN/GTN composite electrode and dried in room temperature for $10 \mathrm{~min}$. The obtained $\mathrm{Hb}$ immobilized 
GN/GTN composite electrode was gently rinsed in distilled water to remove the loosely bound $\mathrm{Hb}$ on the electrode surface. The Hb immobilized GN and GTN modified electrodes was also prepared by the similar procedure without GTN and GN. The modified electrodes were stored in PBS at $4{ }^{\circ} \mathrm{C}$ when not in use and the electrochemical experiments were performed in ambient conditions in inert nitrogen atmosphere.

\section{Results and discussion}

Characterization of GN/GTN composite. - The surface morphology of the pristine GN, GN/GTN composite and $\mathrm{Hb}$ immobilized GN/GTN composite was investigated by SEM and the surface morphological results are shown in Fig. 1A and B. It can be seen from the Fig. 1A that the pristine GN reveals its typical flake structure morphology [28]. Whereas, the as-prepared GN/GTN composite (Fig. 1B) shows distinct morphology when compared to the morphology of pristine GN; in addition, well separated nano GNs were observed in GN dispersed GTN solution, which indicates the high dispersion ability of GN into the GTN solution. In addition, the GN was homogeneously distributed on the GTN matrix with a diameter of few hundred nanometers. The strong interaction between the hydrophobic amino chains of GTN with hydrophobic GNs nanosheets are resulting to the high dispersion ability of GN in GTN solution. The presence of GN in GN/GTN composite was further confirmed by XRD and shown in Fig. 1C. A strong diffraction peak was observed at $2 \theta=26.5$ and is resulting from the strong reflections of the graphitic carbon planes ((002) and (004)) at GN. The similar XRD observations have been reported earlier for pristine GN [38, 39]. The purity of the utilized GN in the GN/GTN composite was examined by Raman spectroscopy and the Raman spectrum of GN is shown in Fig. 1D. The Raman spectrum of GN shows two characteristic peaks at 1589 and $2723 \mathrm{~cm}^{-1}$, is attributed to the $\mathrm{G}$ and $2 \mathrm{D}$ bands, respectively. The intensity ratio of $\mathrm{G}$ and $2 \mathrm{D}$ bands (G/2D) of GN was calculated as 0.91, which indicates that presence of few-layered GN domains [40]. In addition, the highly symmetrical 2D peak of GN indicates that the surface of GN is comprised by single or few layers [41]. On the other hand, the observed peak intensity of D band $\left(1402 \mathrm{~cm}^{-1}\right)$ is relatively low which further confirms the presence of slight number of defects and high quality of GN [40]. The similar phenomenon has been reported elsewhere for the Raman spectrum of pristine GN [40, 41].

The presence of $\mathrm{Hb}$ on the GN/GTN composite modified electrode was confirmed by UV-Vis spectroscopy. Since, UV-Vis spectrum of heme group provides the useful information from the position of the Soret absorption band of proteins [36]. Fig. S1 shows UV-Vis spectra of pure $\mathrm{Hb}$ (a) and $\mathrm{Hb}$ immobilized GN/GTN composite (b). The UV-Vis spectra of pure Hb shows the Soret band at $407 \mathrm{~nm}$, which is very similar to the Soret absorption band for native Hb [36]. While, the $\mathrm{Hb}$ immobilized GN/GTN composite shows the Soret band at $408 \mathrm{~nm}$ and the observed value is close to Soret absorption band for native $\mathrm{Hb}$. The result indicates that there are suitable changes to the morphology and conformation of $\mathrm{Hb}$ in the GN/GTN composite. The result indicates the presence of $\mathrm{Hb}$ in the $\mathrm{GN} / \mathrm{GTN} / \mathrm{Hb}$ composite.

Electrochemical behavior of Hb. - The direct electrochemistry of $\mathrm{Hb}$ was investigated at different modified electrodes in $\mathrm{N}_{2}$ saturated PBS. Fig. 2 shows the cyclic voltammetric response of $\mathrm{Hb}$ immobilized at a bare (a), GTN (b), GN (c) and GN/GTN composite (d) modified electrodes at a scan rate of $100 \mathrm{mV} \mathrm{s}^{-1}$. It can be seen that $\mathrm{Hb}$ immobilized bare and $\mathrm{GN}$ modified electrodes did not show any obvious electrochemical response for $\mathrm{Hb}$. While, the $\mathrm{Hb}$ immobilized GTN modified electrode shows a weak cathodic peak at $-0.366 \mathrm{~V}$, and did not show 
the reversible anodic peak. On the other hand, the $\mathrm{Hb}$ immobilized GN/GTN composite modified electrode shows a good redox couple with a formal potential $\left(\mathrm{E}^{\circ}\right.$, defined as $\left.\left(\mathrm{E}_{\mathrm{pa}}+\mathrm{E}_{\mathrm{pc}}\right) / 2\right)$ of $0.306 \mathrm{~V}$, which is attributed to the presence of reversible electron transfer nature of heme redox couple $\left(\mathrm{Fe}^{\mathrm{II}} / \mathrm{Fe}^{\mathrm{III}}\right)$ in $\mathrm{Hb}[36,42]$. The peak-to-peak separation $\left(\Delta \mathrm{E}_{\mathrm{p}}\right.$, defined as $\left.\mathrm{E}_{\mathrm{pa}}-\mathrm{E}_{\mathrm{pc}}\right)$ was calculated as $101 \mathrm{mV}$. The high conductivity of GN and good biocompatibility of GTN contribute to the clear redox electrochemical behavior of $\mathrm{Hb}$ on GN/GTN composite modified electrode. It should also be noted that the direct electron transfer of $\mathrm{Hb}$ is greatly enhanced in the presence of both GN and GTN when compared to the response observed on GN and GTN modified electrodes. We have also investigated the direct electrochemistry of $\mathrm{Hb}$ with respect to the initial concentration of GN dispersed GTN solutions. The experimental conditions are similar as of in Fig. 2 and the results are shown in Fig. S2. We have only measured the cathodic peak current response of $\mathrm{Hb}$ for optimizing the loading of GN in GN/GTN composite, since the GTN modified electrode shows only a cathodic peak current response to $\mathrm{Hb}$ rather than an anodic peak current response. As shown in Fig. S2, a maximum cathodic peak current response of $\mathrm{Hb}$ was observed for $5 \mathrm{mg} / \mathrm{mL}$ GN dispersed GTN solution. Hence, $5 \mathrm{mg} / \mathrm{mL}$ GN dispersed GTN solution was used as an optimum for further electrochemical investigations. We have also investigated the direct electrochemistry of $\mathrm{Hb}$ in $\mathrm{Hb}$ dispersed GN/GTN composite and the results are compared with $\mathrm{Hb}$ drop coated GN/GTN composite. Fig. S3 shows the cyclic voltammetric response of $\mathrm{Hb}$ drop coated GN/GTN composite (b) and Hb dispersed GN/GTN composite (a) modified electrodes in $\mathrm{N}_{2}$ saturated PBS at a scan rate of $100 \mathrm{mV} \mathrm{s}{ }^{-1}$. It can be seen that a well-defined redox couple of $\mathrm{Hb}$ was observed for $\mathrm{Hb}$ drop coated GN/GTN composite than that of $\mathrm{Hb}$ dispersed GN/GTN composite (a) modified electrode. The result indicates that $\mathrm{Hb}$ drop coated GN/GTN composite modified electrode is more suitable for biosensor construction and further electrochemical studies. The average surface concentration of electroactive $\mathrm{Hb}(\Gamma)$ on GN/GTN composite electrode was estimated from the Eqn. 1. $\Gamma=\mathrm{Q} / \mathrm{nFA}$

Where $\mathrm{Q}=$ total charge $\left(5.309 \times 10^{-6} \mathrm{C}\right), \mathrm{n}=$ number of electrons transferred in the reaction $(\mathrm{n}=1), \mathrm{F}=$ Faraday constant $\left(96485.34 \mathrm{C} \mathrm{mol}^{-1}\right)$ and $\mathrm{A}=$ active surface area of GCE $\left(0.31 \mathrm{~cm}^{2}\right)$. The surface coverage concentration $(\Gamma)$ of $\mathrm{Hb}$ at GN/GTN composite modified electrode was calculated as $1.77 \times 10^{-10} \mathrm{~mol} \mathrm{~cm}{ }^{-2}$. The observed value was higher than that of theoretical monolayer value of $\mathrm{Hb}$ and larger than previously reported $\mathrm{Hb}$ immobilized nanomaterials modified electrodes [36, 42-44]. The result reveals that the GN/GTN composite is favorable for entrapment of more $\mathrm{Hb}$ and retains its native electrochemical activity on the modified electrode.

The effect of scan rate on the $\mathrm{Hb}$ immobilized GN/GTN composite modified electrode was investigated by cyclic voltammetry and the results are shown in Fig. 3A. The redox peak currents $\left(\mathrm{I}_{\mathrm{pa}}\right.$ and $\left.\mathrm{I}_{\mathrm{pc}}\right)$ of $\mathrm{Hb}$ increases with increasing the scan rates; while the $\Delta \mathrm{E}_{\mathrm{p}}$ increases linearly with varying the scan rates from 10 to $200 \mathrm{mV} \mathrm{s}^{-1}$. As shown in Fig. 3B, the $\mathrm{I}_{\mathrm{pa}}$ and $\mathrm{I}_{\mathrm{pc}}$ had a linear dependence over the scan rate from 10 to $200 \mathrm{mV} \mathrm{s}^{-1}$ with the correlation coefficient of 0.996 and 0.9932 . The result further confirms that the redox electrochemical reaction of $\mathrm{Hb}$ on GN/GTN composite modified electrode is controlled by a typical surface-confined reversible electron transfer process [43]. The apparent heterogeneous electron transfer rate constant (Ks) of $\mathrm{Hb}$ immobilized on GN/GTN composite modified electrode was estimated (the scan rate was chosen when the $\Delta_{\mathrm{Ep}}$ is equal or more than $200 \mathrm{mV}$ ) as $3.78 \mathrm{~s}^{-1}$ using Laviron equation for surface-controlled electrochemical system [36]. The calculated $\mathrm{K}_{\mathrm{s}}$ value is much higher than the previously reported $\mathrm{Hb}$ immobilized modified electrodes [36, 42, 43]. The result confirms that 
GN/GTN composites facilitate the direct electron transfer of $\mathrm{Hb}$ and resulting to the fast direct electron transfer towards the electrode surface.

The electrochemical behavior of $\mathrm{Hb}$ is much dependent on the $\mathrm{pH}$ of the solution, hence we have studied the effect of $\mathrm{pH}$ on the electrochemical behavior of $\mathrm{Hb}$ immobilized GN/GTN composite modified electrode in $\mathrm{N}_{2}$ saturated different $\mathrm{pH}(\mathrm{pH} \mathrm{5,7,9}$ and 11) at a scan rate of $100 \mathrm{mVs}^{-1}$. It can be seen from the Fig. 3C that a pair of well-defined redox couple of $\mathrm{Hb}$ is observed in each $\mathrm{pH}$. The $\mathrm{E}_{\mathrm{pa}}$ and $\mathrm{E}_{\mathrm{pc}}$ shifts towards negative and positive direction upon increasing and decreasing the $\mathrm{pH}$. As shown in Fig. 3D, the $\mathrm{E}^{\circ}$ of $\mathrm{Hb}$ has exhibited a linear dependence over a $\mathrm{pH}$ range from $\mathrm{pH} 5$ to 11 with the slope and correlation coefficient of -51.7 $\mathrm{mV} / \mathrm{pH}$ and 0.9936 , respectively. The obtained slope value $(-51.7 \mathrm{mV} / \mathrm{pH})$ is much close to the theoretical value $(-59.0 \mathrm{mV} / \mathrm{pH})$ of the Nernstian equation for equal number of protons $\left(\mathrm{H}^{+}\right)$and electrons ( $\left.\mathrm{e}^{-}\right)$transferred reversible electrochemical process [43]. The result confirms that the direct electrochemical reaction of the redox couple of $\mathrm{Hb}$ is involving of equal number of protons and electrons. Since, the protonation of heme iron in $\mathrm{Hb}$ is involving of single proton and electron transferred electrochemical reaction of $\mathrm{Hb}$ is well documented by others researchers [43].

Amperometric determination of $\mathrm{H}_{2} \mathrm{O}_{2}$. - In order to evaluate the electrocatalytic activity of the $\mathrm{Hb}$ immobilized GN/GTN composite modified electrode, cyclic voltammetry was performed in the absence and presence of different concentration of $\mathrm{H}_{2} \mathrm{O}_{2}$ containing $\mathrm{N}_{2}$ saturated PBS at a scan rate of $100 \mathrm{mV} \mathrm{s}^{-1}$. Fig. 4A shows the cyclic voltammetry response of $\mathrm{Hb}$ immobilized GN/GTN composite modified electrode in the absence (a') and presence of different concentration addition of $\mathrm{H}_{2} \mathrm{O}_{2}(250-1000 \mu \mathrm{M}$, a-e) into the PBS. It can be seen that a stable and well-defined redox couple was observed in the absence of $\mathrm{H}_{2} \mathrm{O}_{2}$. In the presence of $250 \mu \mathrm{M}$ $\mathrm{H}_{2} \mathrm{O}_{2}$ (a), the cathodic peak current of $\mathrm{Hb}$ increased dramatically and anodic peak current decrease simultaneously, indicating the typical electro-reduction of $\mathrm{H}_{2} \mathrm{O}_{2}$ by $\mathrm{Hb}$. The cathodic peak current was increased gradually and the anodic peak was disappeared slowly upon increasing the addition of $\mathrm{H}_{2} \mathrm{O}_{2}$ from $500 \mu \mathrm{M}$ to $1 \mathrm{mM}$ (b-d). Furthermore, the cathodic peak potential was shifted towards the positive potential, which is considered as electrocatalysis of $\mathrm{H}_{2} \mathrm{O}_{2}$ by $\mathrm{Hb}$. In order to further verify the electrocatalytic behavior of $\mathrm{Hb}$, the cyclic voltammetry was performed for the GN/GTN composite modified electrode in $750 \mu \mathrm{M} \mathrm{H}_{2} \mathrm{O}_{2}$ containing $\mathrm{N}_{2}$ saturated PBS at a scan rate of $100 \mathrm{mV} \mathrm{s}^{-1}$ and results are shown in Fig. 4B. The GN/GTN composite modified electrode (a) shows that the peroxide reduction does not occur in the absence of $\mathrm{Hb}$, which indicates that GR/GTN composite does not contribute to the peroxide reduction current. While, $\mathrm{Hb}$ immobilized GN/GTN composite modified electrode (b) shows a sharp reduction current response at a potential of $-0.302 \mathrm{~V}$. The result indicates that the peroxide reduction is due to the presence of $\mathrm{Hb}$ on GN/GTN composite modified electrode.

Amperometric $i$ - $t$ measurements were performed for the determination of $\mathrm{H}_{2} \mathrm{O}_{2}$ using the $\mathrm{Hb}$ immobilized GN/GTN composite modified electrode. Fig. 5A shows the amperometric response of $\mathrm{Hb}$ immobilized GN/GTN composite modified RDE for the addition of different concentration $(0.1-846.6 \mu \mathrm{M})$ of $\mathrm{H}_{2} \mathrm{O}_{2}$ in $\mathrm{N}_{2}$ saturated constantly stirred PBS with a working potential of $-0.32 \mathrm{~V}$. The negative overpotential $(-0.32 \mathrm{~V})$ is more beneficial for high selectivity of the biosensor in presence of common interfering species, since the oxygen reduction is minimum in negative working overpotential. It can be seen from Fig. 5A inset that a stable and well-defined amperometric response is observed for the addition of $0.1,0.5$ and $1 \mu \mathrm{M} \mathrm{H}_{2} \mathrm{O}_{2}$, which indicates the high electrocatalytic ability of the biosensor towards the reduction of $\mathrm{H}_{2} \mathrm{O}_{2}$. 
The response time of the biosensor was calculated as $3 \mathrm{~s}$, and the short response time is due to the rapid electrocatalytic reduction $\mathrm{H}_{2} \mathrm{O}_{2}$ on the biosensor electrode surface. The amperometric response of the biosensor was linear over the concentration of $\mathrm{H}_{2} \mathrm{O}_{2}$ from 0.1 to $786.6 \mu \mathrm{M}$ (Fig. 5B) with the sensitivity of $0.48 \mu \mathrm{A}_{\mu} \mathrm{M}^{-1} \mathrm{~cm}^{-2}$. The limit of detection was calculated as $0.04 \mu \mathrm{M}$ using the standard formula $(\mathrm{S} / \mathrm{N}=3)$. In order to evaluate the superiority of $\mathrm{H}_{2} \mathrm{O}_{2}$ biosensor, the analytical performance of the biosensor was compared with previously reported heme proteins based $\mathrm{H}_{2} \mathrm{O}_{2}$ biosensors and the comparative results are shown in Table. 1. It can be seen from the Table. 1, the proposed biosensor shows the same or comparable analytical performance over the previously reported $\mathrm{H}_{2} \mathrm{O}_{2}$ biosensors [36, 45-53]. The high conductivity of $\mathrm{GN}$ and good biocompatibility of GTN is resulting to the advanced analytical performance of the sensing device.

The selectivity of the biosensor is important for practical applications especially in amperometric biosensors; since, the electroactive species such as dopamine (DA), ascorbic acid, uric acid, glucose and metal ions might interfere with the detection of $\mathrm{H}_{2} \mathrm{O}_{2}$. Hence, the selectivity of the biosensor was investigated using the amperometric method for the response to the addition of $1 \mu \mathrm{M} \mathrm{H}_{2} \mathrm{O}_{2}$ (a) and 100 fold additions $(100 \mu \mathrm{M})$ of the interfering species in to the electrolyte solution and the results are shown in Fig. 6C. The experimental conditions and parameters are similar as of in Fig. 5A. It can be seen that a stable and sharp amperometric response is observed for the addition of $1 \mu \mathrm{M} \mathrm{H}_{2} \mathrm{O}_{2}$, while the interfering species do not show any apparent response on the biosensor electrode. On the other hand, the 100 fold additions of DA show a slight response on the biosensor. However, the response of DA is negligible when compared to the response of $\mathrm{H}_{2} \mathrm{O}_{2}$. The result indicates that the $\mathrm{Hb}$ immobilized GN/GTN composite modified electrode is highly selective towards the detection of $\mathrm{H}_{2} \mathrm{O}_{2}$ and can be used for practical applications.

The practical ability of the biosensor towards the detection of $\mathrm{H}_{2} \mathrm{O}_{2}$ was investigated in the real samples by using amperometry. The fabricated biosensor was applied for the detection of $\mathrm{H}_{2} \mathrm{O}_{2}$ in commercial contact lens cleaning solution and human serum samples by using the standard addition method. The unknown concentration of $\mathrm{H}_{2} \mathrm{O}_{2}$ was predetermined as $3.2 \mu \mathrm{M}$ in commercial contact lens cleaning solution by amperometry. Then, the known concentration of $\mathrm{H}_{2} \mathrm{O}_{2}(3 \mu \mathrm{M})$ containing commercial contact lens cleaning solution and human serum samples were spiked into the PBS. The obtained recovery values for $\mathrm{H}_{2} \mathrm{O}_{2}$ in commercial contact lens solution and human serum samples are summarized in Table ST1. It can be seen that the recoveries of $\mathrm{H}_{2} \mathrm{O}_{2}$ in the ranging from 95.2 to $97.8 \%$ in commercial contact lens solution and 101.7 to $102.0 \%$ in human serum samples indicating its applicative potential.

The operational stability of the biosensor was investigated by amperometric method and the experimental conditions are similar as in Fig. 5A. Fig. 6B shows the amperometric $i-t$ response of $\mathrm{Hb}$ immobilized GN/GTN composite modified RDE for the addition of $50 \mu \mathrm{M} \mathrm{H}_{2} \mathrm{O}_{2}$ (a) into continuously stirred $\mathrm{N}_{2}$-saturated PBS up to $1800 \mathrm{~s}$. The response current of $\mathrm{H}_{2} \mathrm{O}_{2}$ was lost only $8.6 \%$ after continues run up to $2000 \mathrm{~s}$, which indicates the high operational stability of the biosensor. We have also performed the stability of the Hb on GN/GTN composite modified electrode by using the cyclic voltammetry. Fig. 6A shows the 15 consecutive cyclic voltammetry response of $\mathrm{Hb}$ immobilized GN/GTN composite modified electrode in $\mathrm{N}_{2}$ saturated PBS at a scan rates of $100 \mathrm{mV} \mathrm{s}^{-1}$. The $\mathrm{Hb}$ immobilized GN/GTN composite modified electrode retains about $96.7 \%$ of its initial current response to $\mathrm{Hb}$ after 15 consecutive cycles, which indicates the high cyclic stability of $\mathrm{Hb}$ on GN/GTN composite modified electrode. In addition, the stability of $\mathrm{Hb}$ immobilized GN/GTN composite modified electrode was studied by $\mathrm{CV}$ at different time 
intervals $(0,30,60$ and $90 \mathrm{~min})$ in PBS and the obtained results are shown in Fig. S4. It can be clearly seen from Fig. S4 that the redox couple of $\mathrm{Hb}$ was slightly decreased after $30 \mathrm{~min}$ (b) in PBS and the redox peaks are almost unchanged after 60 (c) and 90 (d) min, which indicates that $\mathrm{Hb}$ was firmly adsorbed on the modified electrode surface. The reproducibility and repeatability of the biosensor for the detection of $250 \mu \mathrm{M} \mathrm{H}_{2} \mathrm{O}_{2}$ was investigated by cyclic voltammetry and experimental conditions are similar as shown in Fig. 4A. The five independently prepared biosensors show an acceptable reproducibility with a relative standard deviation (RSD) of $4.4 \%$ for detection of $\mathrm{H}_{2} \mathrm{O}_{2}$. The repeatability of the biosensor for 8 measurements was found with a RSD of $2.9 \%$ for detection of $\mathrm{H}_{2} \mathrm{O}_{2}$. The result indicates the biosensor has appropriate repeatability and reproducibility.

\section{Conclusions}

In conclusion, we have prepared $\mathrm{Hb}$ immobilized GN/GTN composite modified electrode for construction of novel $\mathrm{H}_{2} \mathrm{O}_{2}$ biosensor. The as prepared biosensor exhibited a high catalytic activity towards the detection of $\mathrm{H}_{2} \mathrm{O}_{2}$. The $\mathrm{Hb}$ immobilized GN/GTN composite modified electrode showed many advantages such as wide linear response, good sensitivity and lower LOD for the detection of $\mathrm{H}_{2} \mathrm{O}_{2}$. In addition, the biosensor exhibited similar or better analytical performance towards $\mathrm{H}_{2} \mathrm{O}_{2}$ when compared with the previously reported heme proteins based $\mathrm{H}_{2} \mathrm{O}_{2}$ biosensors. The biosensor also exhibited the good selectivity along with good practicality for the detection of $\mathrm{H}_{2} \mathrm{O}_{2}$ in the commercial solution and human serum samples. As a future perspective, the proposed biosensor can be used for the sensitive and selective detection of $\mathrm{H}_{2} \mathrm{O}_{2}$ in the real samples with high precision.

\section{Acknowledgements}

This work was supported by the Ministry of Education of Taiwan (Republic of China). The authors express their sincere thanks to Prof. Bih-Show Lou, Chemistry Division, Center for General Education, Chang Gung University, Tao-Yuan, Taiwan for providing the human serum samples. 


\section{References}

1. C.R. Ispas, G. Crivat, and S. Andreescu, Anal. Lett. 45, 168 (2012).

2. Q. Shengz, H. Tang, Y. Wang and J. Zheng, J. Electrochem. Soc. 163, H128 (2016).

3. T. Kuila, S. Bose, P. Khanra, A.K. Mishra, N.H. Kim, and J.H. Lee, Biosens. Bioelectron. 26, 4637 (2011).

4. M. Baccarin, B.C. Janegitz, R. Berté, F.C. Vicentini, C.E. Banks, O. Fatibello-Filho, and V. Zucolotto, Mater. Sci. Eng., C 58, 97 (2015).

5. S. Dong, Z. Li, Z. Yu, Y. Zhou, and H. Tang, Colloids Surf., B 100, 133 (2012).

6. R. Zhang, X. Wang, and K.K. Shiu, J. Colloid Interface Sci. 316, 517 (2007).

7. Y.Q. Wang, H.J. Zhang, D. Yao, J.J. Pu, Y. Zhang, X.R. Gao, and Y.M. Sun, J. Solid State Electrochem. 17, 881 (2013).

8. E.P. Randviir, D.A.C. Brownson, and C.E. Banks, Materials Today, 17, 426 (2014).

9. W. Choi, I. Lahiri, R. Seelaboyina, and Y.S. Kang, Crit. Rev. Solid State Mater. Sci., 35, 52 (2010).

10. P. Avouris, and C. Dimitrakopoulos, Mater. Today 15, 86 (2012).

11. M.E. Khan, M.M. Khan, and M.H. Cho, RSC Adv., 6, 20824 (2016).

12. M.E. Khan, M.M. Khan, and M.H. Cho, New J. Chem., 39, 8121 (2015).

13. M.E. Khan, M.M. Khan, and M.H. Cho, RSC Adv., 5, 26897 (2015).

14. M. Pumera, A. Ambrosi, A. Bonanni, E.L.K. Chng, and H.L. Poh, Trends Anal. Chem. 29, 954 (2010).

15. Y. Shao, J. Wang, H. Wu, J. Liu, I.A. Aksay, and Y. Lin, Electroanalysis, 22, 1027 (2010).

16. B. Unnikrishnan, S. Palanisamy, and S.M. Chen, Biosens. Bioelectron. 39, 70 (2013).

17. A.T. Lawal, Talanta, 131, 424 (2015).

18. S. Wu, Q. He, C. Tan, Y. Wang, and H. Zhang, Small 9, 1160 (2013).

19. K. Liu, J.J. Zhang, F.F. Cheng, T.T. Zheng, C. Wang, and J.J. Zhu, J. Mater. Chem., 21, 12034 (2011).

20. Y. Ge, J. Wang, Z. Shi, and J. Yin, J. Mater. Chem., 22, 17619 (2012).

21. J.M. Yoo, J.H. Kang, and B.H. Hong, Chem. Soc. Rev., 44, 4835 (2015).

22. X.Y. Chen, C. Chen, Z.J. Zhang, and D.H. Xie, J. Mater. Chem. A, 1, 10903 (2013).

23. S. Haider, S.Y. Park, K. Saeed, and B.L. Farmer, Sens. Actuators, B 124, 517 (2007).

24. A.P. Periasamy, Y.J. Chang, and S.M. Chen, Bioelectrochemistry 80, 114 (2011).

25. H. Li, D.Q. Wang, B.L. Liu, and L.Z. Gao, Colloids Surf., B 33, 85 (2004).

26. W. Zheng, and Y.F. Zheng, Electrochem. Commun. 9, 1619 (2007).

27. P.N. Bartlett, P.R. Birkin, J.H. Wang, F. Palmisano, and G.D. Benedetto, Anal. Chim. Acta 70, 3685 (1998).

28. R.M. Sellers, Analyst 105, 950 (1980).

29. M.M. Khan, S.A. Ansari, J. Lee, and M.H. Cho, Mater. Sci. Eng., C 33, 4692 (2013).

30. C. Priya, G. Sivasankaria, and S. Sriman Narayanan, Colloids Surf., B 97, 90 (2012).

31. C. Matsubara, and N. Kawamoto, K. Takamura, Analyst 117, 1781 (1992).

32. S. Hanaoka, J.M. Lin, and M. Yamada, Anal. Chim. Acta 426, 57 (2001).

33. J. Li, S.N. Tan, and H.L. Ge, Anal. Chim. Acta 335, 137 (1996).

34. M.G. Garguilo, A. Proctor, and A.C. Michael, Anal. Chem. 65, 523 (1993).

35. J. Liu, C. Guo, C.M. Li, Y. Li, Q. Chi, X. Huang, L. Liao, and T. Yu, Electrochem. Commun. 11, 202 (2009).

36. S. Palanisamy, S. Cheemalapati, and S.M. Chen, Anal. Biochem. 429, 108 (2012).

37. W. Chen, S. Cai, Q.Q. Ren, W. Wen, and Y.D. Zhao, Analyst, 137, 49 (2012). 
38. C. Karuppiah, S. Palanisamy, S.M. Chen, V. Veeramani, and P. Periakaruppan, Sens. Actuators, B 196, 450 (2014).

39. Y. Ge, J. Wang, Z. Shi, and J. Yin, J. Mater. Chem., 22, 17619 (2012).

40. D.A.C. Brownson, S.A. Varey, F. Hussain, S.J. Haigh, and Craig E. Banks, Nanoscale, 6, 1607 (2014).

41. A.C. Ferrari, J.C. Meyer, V. Scardaci, C. Casiraghi, M. Lazzeri, F. Mauri, S. Piscanec, D. Jiang, K.S. Novoselov, S. Roth, and A.K. Geim, Phys. Rev. Lett. 97, 187401 (2006).

42. T. Mondal, A.K. Bhowmick, and R. Krishnamoorti, J. Mater. Chem., 22, 22481 (2012).

43. B. Habibi, and M. Jahanbakhshi, Microchim. Acta 182, 957 (2015).

44. M.A. Aref, J.B. Raoof, F. Kiekens, and K.D. Wael, Biosens. Bioelectron. 74, 518 (2015).

45. K.J. Huang, D.J. Niu, X. Liu, Z.W. Wu, Y. Fan, Y.F. Chang, and Y.Y. Wu, Electrochim. Acta 56, 2947 (2011).

46. L. Xie, Y. Xu, and X. Cao, Colloids Surf., B 107, 245 (2013).

47. W. Ma, and D. Tian, Bioelectrochemistry 78, 106 (2010).

48. S. Lata, B. Batra, N. Karwasra, and C.S. Pundir, Process Biochem. 47, 992 (2012).

49. A. Sun, Q. Sheng, and J. Zheng, Appl. Biochem. Biotechnol. 166, 764 (2012).

50. J. Xu, C. Liu, and Z. Wu, Microchim. Acta 172, 425 (2011).

51. Y. He, Q. Sheng, J. Zheng, M. Wang, and B. Liu, Electrochim. Acta 56, 2471 (2011).

52. Q. Feng, K. Liu, J. Fu, Y. Zhang, Z. Zheng, C. Wang, Y. Du, and W. Ye, Electrochim. Acta 60, 304 (2012).

53. K. Liu, J. Zhang, G. Yang, C. Wang, and J.J. Zhu, Electrochem. Commun. 12, 402 (2010). 
Table. 1 Comparison of analytical performance of the fabricated $\mathrm{H}_{2} \mathrm{O}_{2}$ biosensor with previously reported heme proteins based $\mathrm{H}_{2} \mathrm{O}_{2}$ sensors.

\begin{tabular}{lcccc}
\hline Electrode & $\begin{array}{c}\text { Linear range } \\
(\boldsymbol{\mu} \mathbf{M})\end{array}$ & $\begin{array}{c}\text { Sensitivity } \\
\left(\boldsymbol{\mu} \mathbf{A ~ m M}^{-1} \mathbf{~ m}^{-2}\right)\end{array}$ & $\begin{array}{c}\text { LOD } \\
(\boldsymbol{\mu M})\end{array}$ & Reference \\
\hline $\mathrm{MWCNT/ZnO/Hb/GCE}$ & $0.1-36.6$ & 366.0 & 0.02 & 36 \\
\hline $\mathrm{Ca} / \mathrm{AuNP} / \mathrm{GR}-\mathrm{NH} / \mathrm{GCE}$ & $0.3-600.0$ & 13.4 & 0.05 & 45 \\
\hline $\mathrm{Hb} / \mathrm{AuNP} / \mathrm{ZnO} / \mathrm{GR} / \mathrm{GCE}$ & $6-1130$ & $\mathrm{NA}$ & 0.8 & 46 \\
\hline $\mathrm{MWCNT/ZnO/Hb/GCE}$ & $0.2-12.0$ & 1.31 & 0.084 & 47 \\
\hline $\mathrm{NiO}-\mathrm{NP} / \mathrm{MWCNT} / \mathrm{PAN} / \mathrm{CytC} / \mathrm{GCE}$ & $3-700.0$ & 330.0 & 0.2 & 48 \\
\hline $\mathrm{GN} / \mathrm{CS} / \mathrm{PdNPs} / \mathrm{Hb} / \mathrm{GCE}$ & $2.0-1100$ & 0.2 & 0.66 & 49 \\
\hline $\mathrm{GN} / \mathrm{ZnO} / \mathrm{Hb} / \mathrm{GCE}$ & $1.8-2300$ & $\mathrm{NA}$ & 0.6 & 50 \\
\hline $\mathrm{Fe}_{3} \mathrm{O}_{4}-\mathrm{GN} / \mathrm{Hb} / \mathrm{GCE}$ & $1.5-585.0$ & $\mathrm{NA}$ & 0.5 & 51 \\
\hline $\mathrm{Hb} / \mathrm{AuNP} / \mathrm{PDDA}-\mathrm{G} / \mathrm{GCE}$ & $6.0-1010.0$ & $\mathrm{NA}$ & 0.39 & 52 \\
\hline $\mathrm{GN} / \mathrm{Fe}_{3} \mathrm{O}_{4}-\mathrm{Hb} / \mathrm{GCE}$ & $0.25-1700.0$ & $\mathrm{NA}$ & 0.6 & 53 \\
\hline $\mathrm{GN} / \mathrm{GTN} / \mathrm{Hb} / \mathrm{GCE}$ & $0.1-786.6$ & 48.0 & 0.04 & This work \\
\hline $\mathrm{Ab}$ & & & &
\end{tabular}

Abbreviations:

LOD - limit of detection; MWCNT - multiwalled carbon nanotubes; $\mathrm{ZnO}$ - zinc oxide; $\mathrm{Hb}$ hemoglobin; Cat - catalase; AuNPs - gold nanoparticles; GR- $-\mathrm{NH}_{2}$ - amine functionalized graphene; GCE - glassy carbon electrode; NiO-NPs - nickel oxide nanoparticles; PANI polyaniline; CytC - cytochrome C; GN - graphene; CS - chitosan; PdNPs - palladium nanoparticles; PDDA-G - poly (diallyldimethylammonium chloride) functionalized graphene. 


\section{Figure captions}

Fig. 1 SEM images of pristine GN (A), GN/GTN composite (B). C) Typical XRD pattern of GN/GTN composite. D) Raman spectrum of GN in GN/GTN composite.

Fig. 2 Cyclic voltammograms obtained at $\mathrm{Hb}$ immobilized bare (a), GTN (b), GN (c) and GN/GTN composite (d) modified electrodes in $\mathrm{N}_{2}$ saturated PBS at a scan rate of $100 \mathrm{mV} \mathrm{s}^{-1}$.

Fig. 3 A) Cyclic voltammograms of $\mathrm{Hb}$ immobilized GN/GTN composite modified electrode in $\mathrm{N}_{2}$ saturated PBS at different scan rates from 10 to $200 \mathrm{mV} \mathrm{s}^{-1}(\mathrm{a}-\mathrm{j})$. B) The corresponding linear dependence plot of anodic (blue profile) and cathodic (red profile) peak currents with scan rate. C) Cyclic voltammograms obtained for $\mathrm{Hb}$ immobilized GN/GTN composite modified electrode

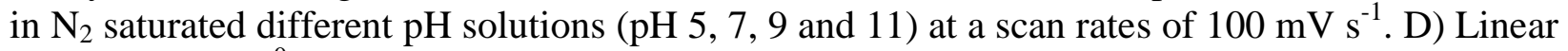
dependence of $\mathrm{E}^{0}$ vs. $\mathrm{pH}$.

Fig. 4 A) Cyclic voltammograms recorded $\mathrm{Hb}$ immobilized GN/GTN composite modified electrode in absence (a') and presence of $250 \mu \mathrm{M}$ (a), $500 \mu \mathrm{M}$ (b), $750 \mu \mathrm{M}$ (c) and $1 \mathrm{mM} \mathrm{H}_{2} \mathrm{O}_{2}$ (d) containing $\mathrm{N}_{2}$ saturated PBS at a scan rates of $100 \mathrm{mV} \mathrm{s}^{-1}$. B) Cyclic voltammetric response of GN/GTN composite (a) and Hb immobilized GN/GTN composite (b) modified electrode in 1 $\mathrm{mM} \mathrm{H} \mathrm{H}_{2} \mathrm{O}_{2}$ containing $\mathrm{N}_{2}$ saturated PBS.

Fig. 5 A) Amperometric $i-t$ response of $\mathrm{Hb}$ immobilized GN/GTN composite modified RDE for successive additions of different concentration of $\mathrm{H}_{2} \mathrm{O}_{2}(0.1$ to $846.6 \mu \mathrm{M})$ into the continuously stirred $\mathrm{N}_{2}$ saturated PBS. Working potential $=-0.32 \mathrm{~V}$. Inset shows enlarged view of the amperometric $\mathrm{i}-\mathrm{t}$ response up to $10.1 \mu \mathrm{M}$. B) Linear dependence of cathodic peak current vs. $\left[\mathrm{H}_{2} \mathrm{O}_{2}\right]$ and the error bar indicates the standard deviation for 3 measurements.

Fig. 6 A) 15 consecutive cyclic voltammetry response of $\mathrm{Hb}$ immobilized GN/GTN composite modified electrode in $\mathrm{N}_{2}$ saturated PBS at a scan rates of $100 \mathrm{mV} \mathrm{s}^{-1}$ (B) Amperometric $i-t$ response of $\mathrm{Hb}$ immobilized GN/GTN composite modified RDE for the addition of $50 \mu \mathrm{M} \mathrm{H}_{2} \mathrm{O}_{2}$ (a) into continuously stirred $\mathrm{N}_{2}$ saturated PBS up to $1800 \mathrm{~s}$. C) Amperometric $i-t$ response of $\mathrm{Hb}$ immobilized GN/GTN composite modified RDE for the addition of $5 \mu \mathrm{M} \mathrm{H}_{2} \mathrm{O}_{2}$ (a), $500 \mu \mathrm{M}$ dopamine (b), $500 \mu \mathrm{M}$ ascorbic acid (c), and $500 \mu \mathrm{M}$ uric acid (d), glucose (e), SO4 ${ }^{2-}$ (f) and $\mathrm{SO}^{2-}(\mathrm{g})$ solutions into the continuously stirred $\mathrm{N}_{2}$-saturated PBS. The experimental conditions for amperometric experiments are similar as of in Fig. 4A. 

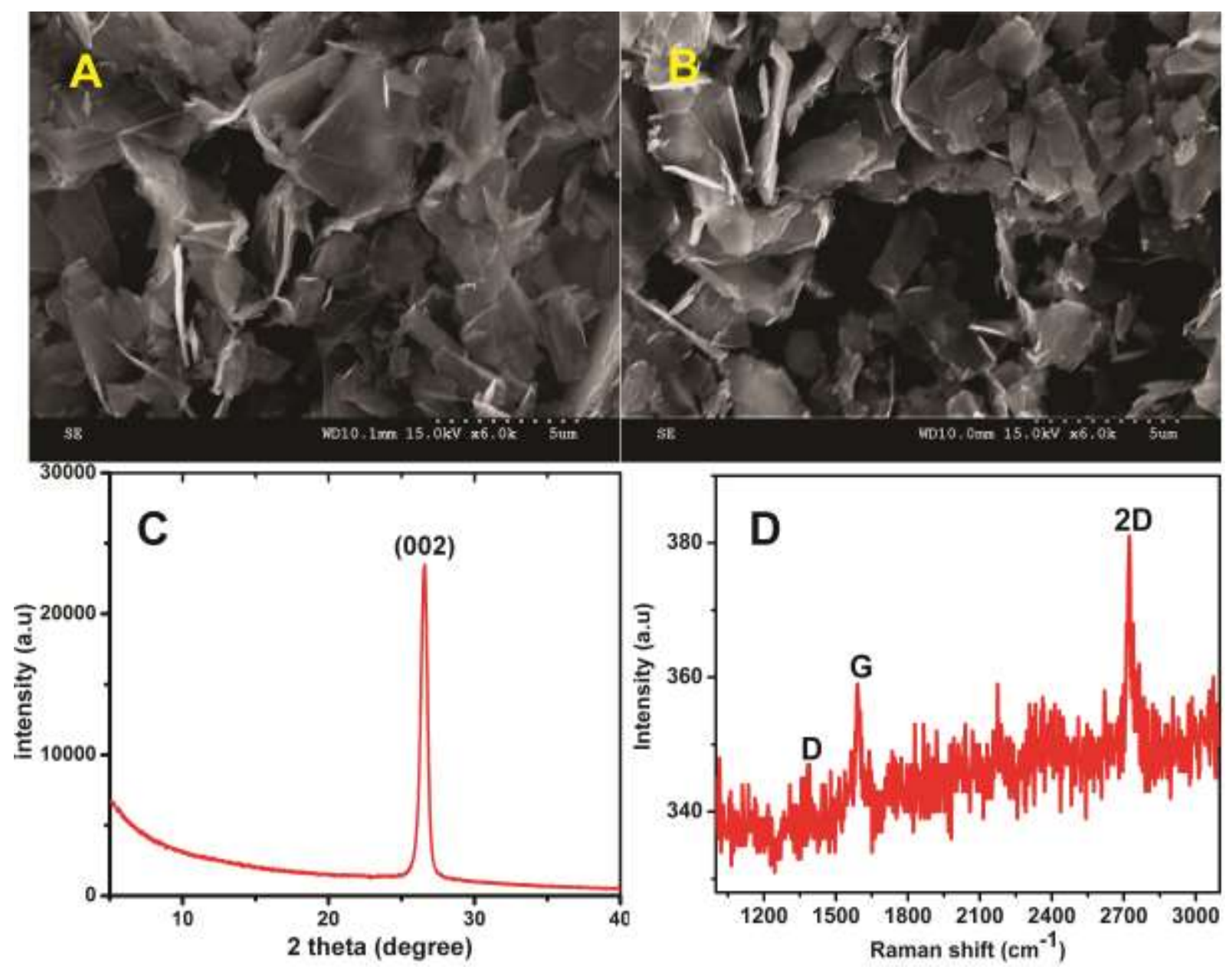

Figure-1 


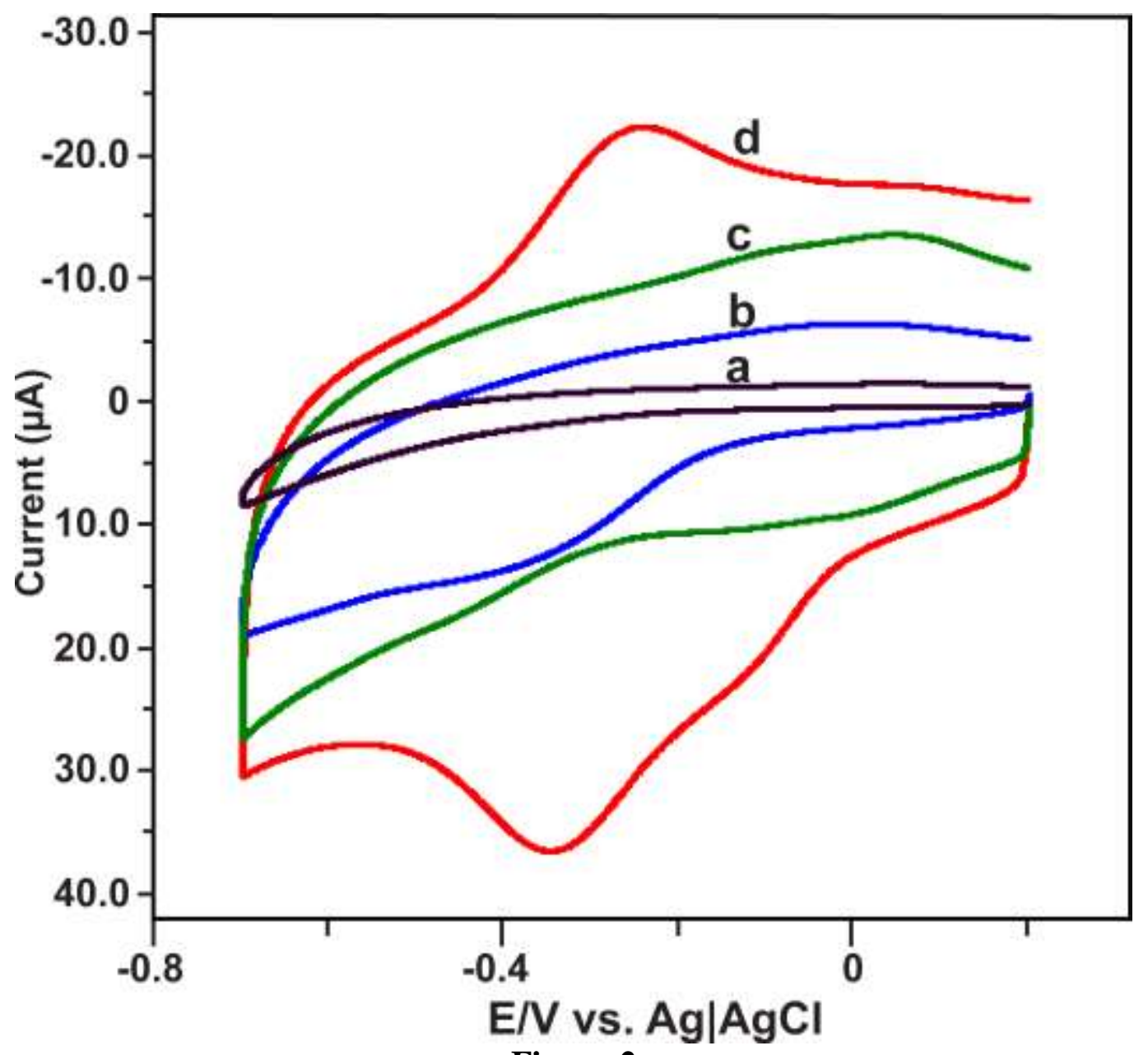

Figure-2 

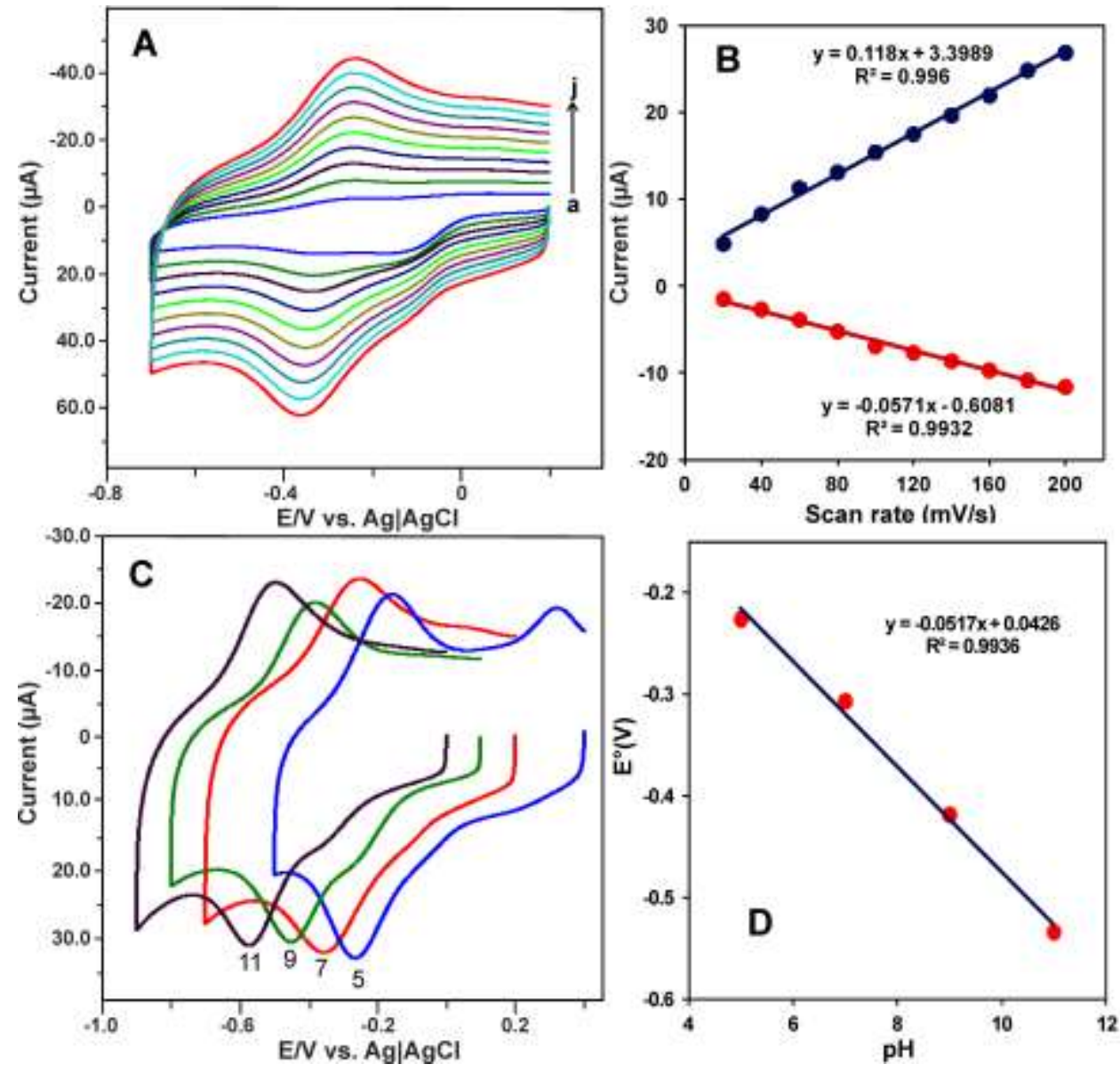

Figure-3 

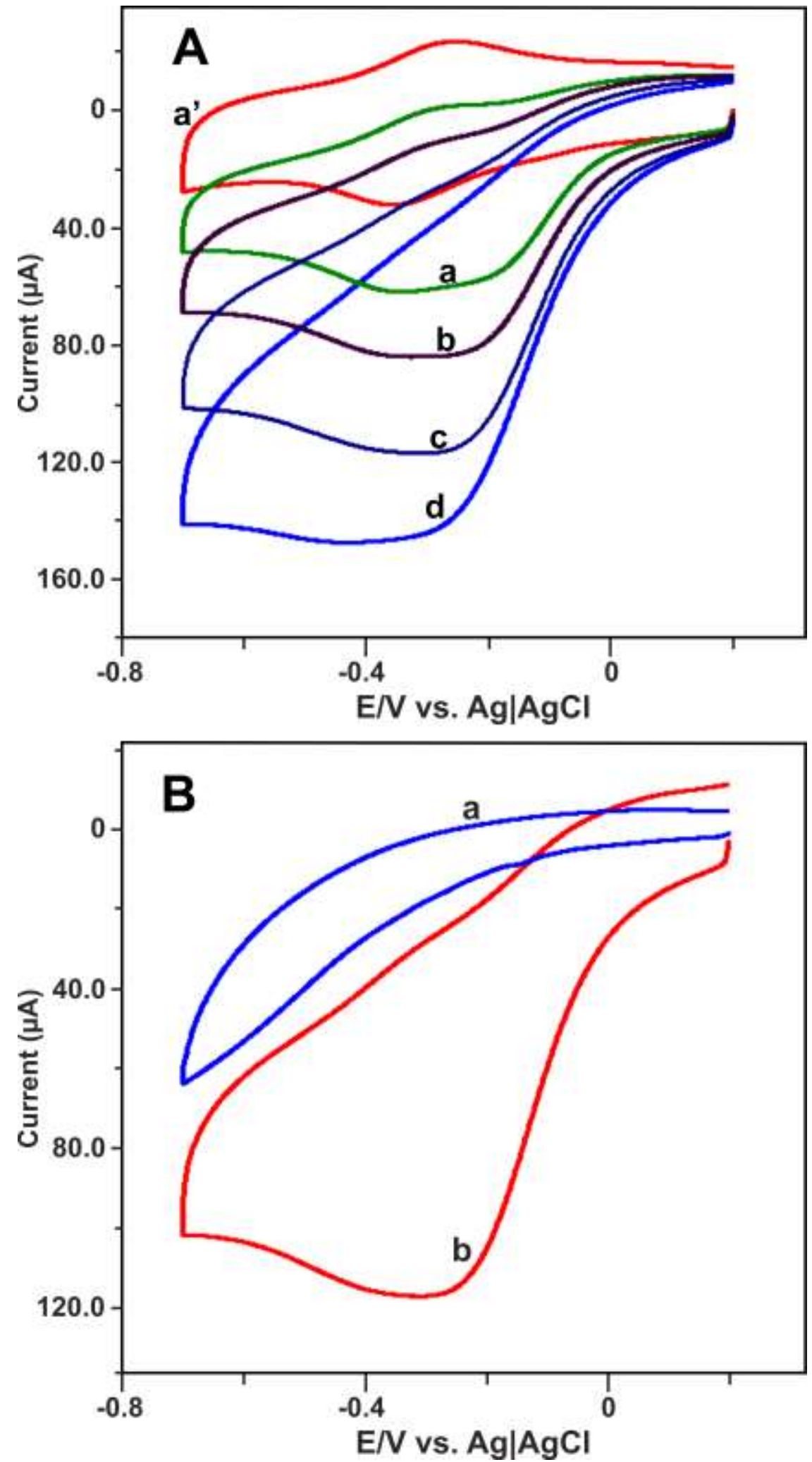

Figure-4 


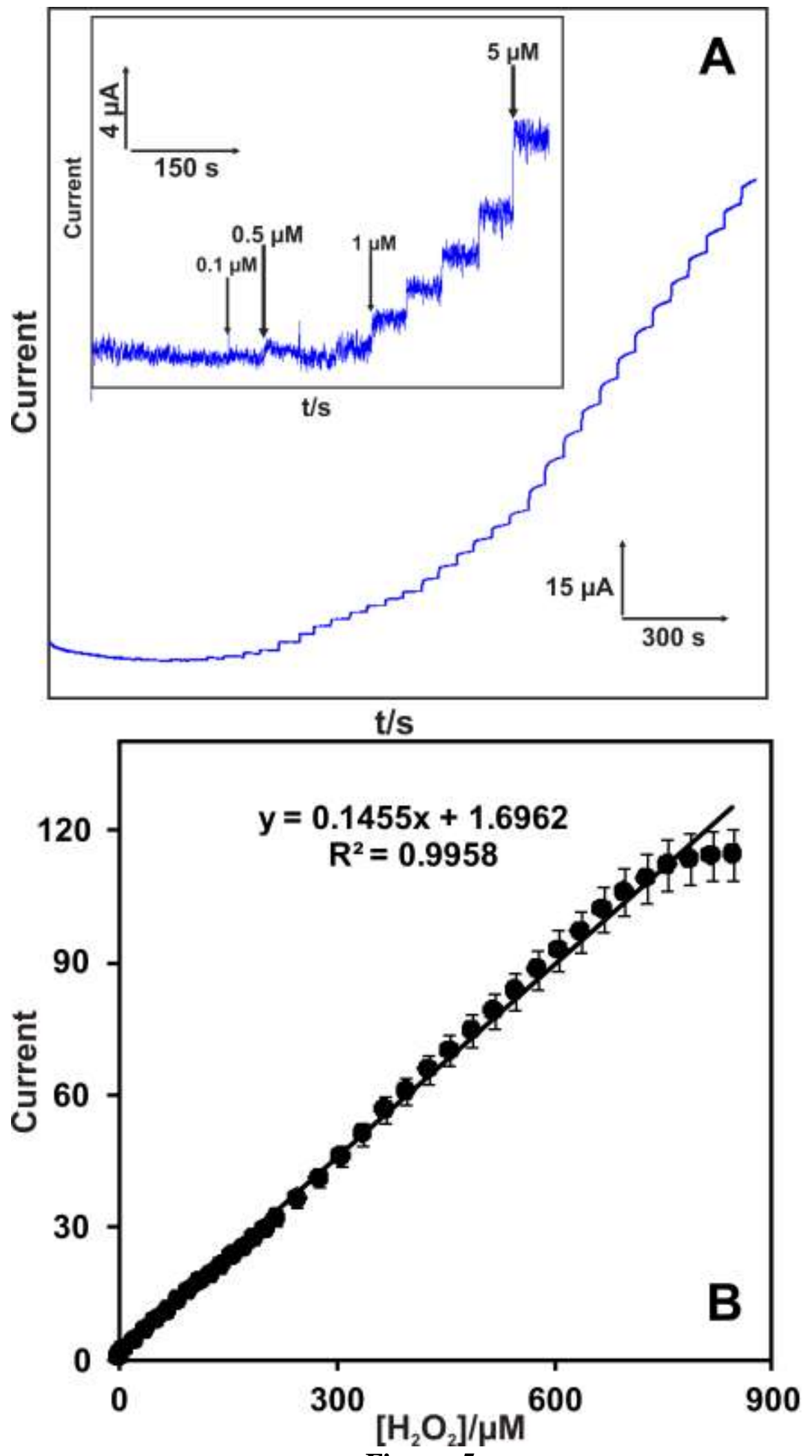

Figure-5 


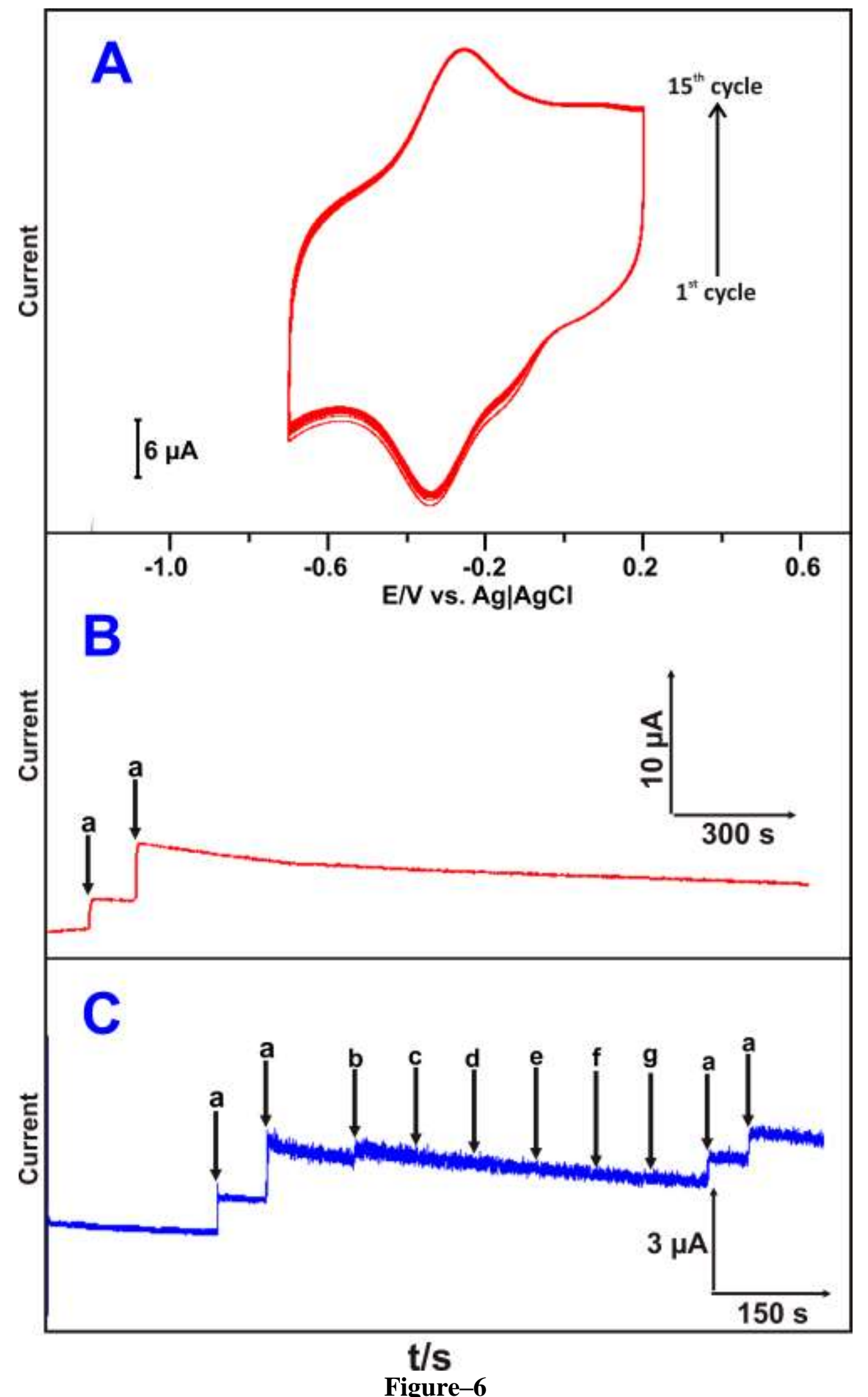

Figure-6 